\title{
Model Test on Segmental Grouting Diffusion Process in Muddy Fault of Tunnel Engineering
}

\author{
Jun Liu, ${ }^{1}$ Qingsong Zhang $\mathbb{D}^{1},{ }^{1}$ Lianzhen Zhang $\mathbb{D}^{2}{ }^{2}$ Fang Peng, ${ }^{3}$ Zhipeng Li, ${ }^{4}$ \\ and Xianjie Weng \\ ${ }^{1}$ Geotechnical and Structural Engineering Research Center, Shandong University, Jinan, China \\ ${ }^{2}$ College of Pipeline and Civil Engineering, China University of Petroleum, Qingdao, China \\ ${ }^{3}$ School of Computer and Information Engineering, Jiangxi Agricultural University, Nanchang, China \\ ${ }^{4}$ School of Transportation and Civil Engineering, Shandong Jiaotong University, Jinan, China \\ ${ }_{5}^{5}$ Jiangxi Provincial Expressway Investment Group, Nanchang, China
}

Correspondence should be addressed to Lianzhen Zhang; zhanglianzhen@upc.edu.cn

Received 8 November 2020; Revised 21 November 2020; Accepted 4 December 2020; Published 21 December 2020

Academic Editor: Bin Gong

Copyright (c) 2020 Jun Liu et al. This is an open access article distributed under the Creative Commons Attribution License, which permits unrestricted use, distribution, and reproduction in any medium, provided the original work is properly cited.

In order to realize the diffusion law of segmental grouting in muddy fault of tunnel engineering, a three-dimensional grouting diffusion simulation test has been done. Three times of grouting operation have been done for three adjacent sections in grouting pipe. Grouting pressure, injection rate, soil pressure field, and seepage pressure field have been real-time monitored in three grouting stages. The effect of segmental grouting operation on soil pressure field and effective stress field has been analyzed. Results show that previous grouting operation can affect later grouting operation. Due to previous grouting operation, the grouted stratum can be compacted and grouting diffusion will conquer greater resistance in later grouting stages. Correspondingly, grouting pressure increases and injection rate decreases in the later grouting stage. There exists a limited influence range for a single grouting operation. For every grouting stage, soil pressure and effective stress in the section which the injection hole locates in are affected effectively by grouting operation. By contrast, soil pressure and effective stress in section away from injection hole are affected relatively weakly by grouting operation. With distance to injection hole increasing, compaction degree and reinforcement effect of grouted muddy fault decay in space. Multisegmental grouting method has significant advantages over single grouting method. Ineffectively compacted area by previous grouting operation can be effectively compacted by later grouting operation from adjacent injection hole. As a result, uniformity of grouting reinforcement effect can be improved, and weakly reinforcement area can be reduced.

\section{Introduction}

Muddy fault is often encountered in tunnel construction, which is characterized by loose structure, no self-stability [1-4]. Grouting is an effective method to reinforce muddy fault [5-7]. Grouting diffusion usually behaves in fracture mode in muddy fault stratum [8-11]. Namely, grout veins form and the stratum on both sides of grout vein are compacted simultaneously in fracture grouting diffusion process. Due to the support effect of grout veins and consolidation effect of grouted stratum, muddy fault stratum is reinforced effectively [12-14].
For the traditional grouting method, a single grouting operation is done in the full length of the injection hole. Grout usually diffuses along the weakest channel in the grouted stratum. As a result, some areas can hardly be reinforced effectively, and a uniform grouted body can hardly be created. By contrast, for the segmental grouting method, the injection hole is divided into several sections and every section will be grouted independently. Grout veins are produced in every section, as a result of which uniformity of grouting reinforcement effect will be greatly improved.

Several studies on fracture grouting have been conducted by many researchers. Zhou and Chen [15] proposed a 
hypothesis that the fracture grouting process can be divided into three stages, namely, bubble compaction stage, fracture flow stage, and passive earth pressure increase stage. Bezuijen [16] performed a model test on fracture grouting process in the sand layer, and propagation path and shape of fracture grouting were acquired by grouted body separation and SEM method. Moreover, the relationship between the shape of grout vein and grouting parameters and characteristics of grouted stratum had been established. Sun et al. [17, 18] and Chen et al. [19] studied the relationship between grout material parameters, grouting design parameters, and distribution rule of grout veins in fracture grouting when considering grout material as a Bingham fluid. They also proposed that the grouting pressure is the main controlling factor of fracture grouting. Li et al. [20] derived a fracture grouting diffusion model based on the rock structure of the water-rich fault zone and the constitutive equation of Bingham's fluid. And the effects of grouting rate, pressure, and slurry viscosity on the grouting diffusion process were analyzed. Yuan et al. [21] simulated fracture grouting process in soft stratum by PFC2D numerical analysis software. And the relationship between effective diffusion radius, grouting parameters, and injected medium parameters was obtained.

Most of the above studies about fracture grouting diffusion mechanism are concentrated on single grouting operation. However, few researches have been done to realize the grouting diffusion law of segmental grouting operation. As a result, the practice of segmental grouting always relies on engineering experience.

In this paper, a three-dimensional simulation test has been done to simulate the segmental grouting diffusion process in the muddy fault of the tunnel. Three times of grouting operation has been done for three adjacent sections in grouting pipe. Grouting pressure, injection rate, soil pressure field, and seepage pressure field have been real-time monitored in three grouting stages. The effect of segmental grouting operation on soil pressure field and effective stress field has been analyzed. The superiority of the segmental grouting method over the single grouting method has been verified.

\section{Three-Dimensional Grouting Simulation Test System}

The three-dimensional grouting simulation test system is composed by a test frame, segmental grouting module, and data monitoring module. The test system is shown in Figure 1. Test frame is a fabricated structure and composed by several semicircular components. The internal space diameter of the test frame is $150 \mathrm{~cm}$ and the height is $120 \mathrm{~cm}$. Before test operation, a muddy fault stratum should be filled into the test frame. With the object to simulate drainage condition in actual projects, a permeable fine sand layer is set between the top cover of the test frame and muddy fault stratum. Excess water in the grouting process can be drained through the permeable fine sand layer.

Segmental grouting module consists of a segmental grouting device in the test frame and supplementary grouting system. A segmental grouting device is a steel grouting pipe

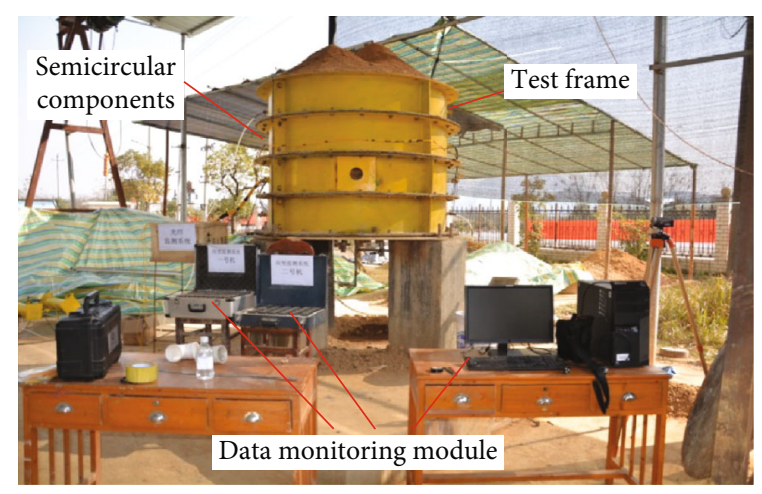

FIgURE 1: Model test system.

in which several expansion separators and injection holes are distributed regularly (as shown in Figure 2). There is a waterproof sand bag in the expansion separator which can prevent the passage of grout. In addition, the waterproof sand bag is easy to be destroyed. After a grouting stage is over, the waterproof sand bag will be destroyed for the passage of grout. As a result, next grouting stage can be operated and the segmental grouting process can be realized.

Supplementary grouting system consists of grouting pump, grouting pipeline, mixing barrel, and double components mixer. The air-powered grouting pump is equipped with a grouting pressure range of $0 \sim 10 \mathrm{MPa}$ and an injection rate range of $0 \sim 12 \mathrm{~L} / \mathrm{min}$.

The data monitoring module consists of a grouting data recorder (as shown in Figure 3) and a pressure field monitoring system (as shown in Figure 4). Grouting data recorder can collect grouting pressure and injection rate in real-time in grouting process, with data collection frequency of 1 time per second. Pressure field monitoring system can collect soil pressure field and seepage pressure field in grouted body in real-time through soil pressure sensor and seepage pressure sensor. The measurement range of the soil pressure sensor in this test is $0 \sim 0.2 \mathrm{MPa}$ and precision is $0.08 \%$ F.S. Measurement range of the seepage pressure sensor is $0 \sim 0.2 \mathrm{MPa}$ and precision is $0.08 \% \mathrm{~F} . \mathrm{S}$, as the same as the soil pressure sensor.

\section{Design of Grouting Test}

3.1. Grouted Stratum. Grouted stratum used in the simulation test was undisturbed muddy fillings in F2 fault of Yonglian Tunnel in Ji-Lian highway in Jiangxi Province of China, which is a very typical engineering project (as shown in Figure 5). Inrush accidents of mud and water happened many times when the tunnel is going through F2 muddy filling fault. Muddy fillings of F2 fault are characterized by loose structure, no self-stability, whose basic physical parameters are shown in Table 1.

3.2. Grout Material. Cement-based quick setting grout was used in the simulation test, which is composed by two components, cement component and accelerator component. The cement used in this test was P.O.42.5 ordinary Portland 


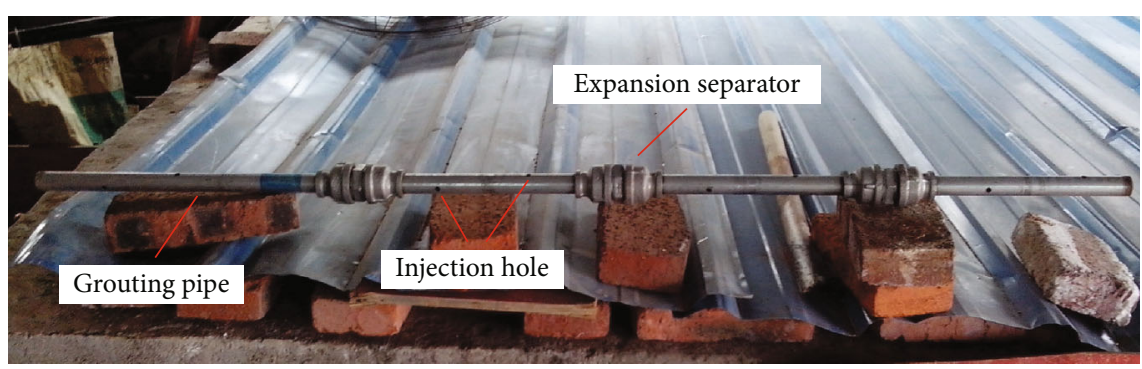

(a) Photo

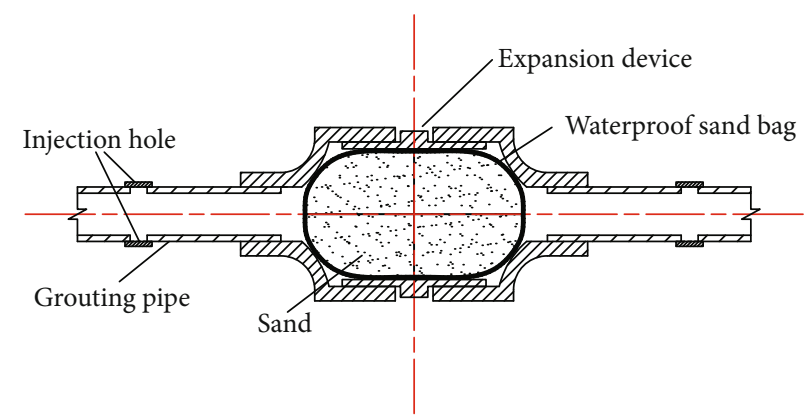

(b) Principle of expansion separator

FIGURE 2: Segmental grouting device in the test frame.

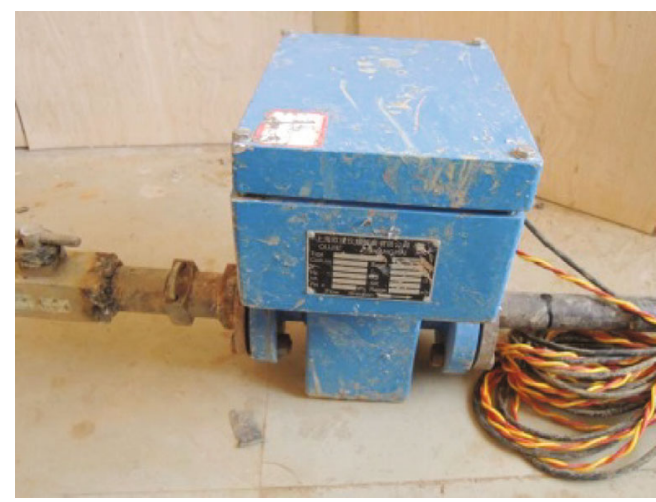

(a) Injection rate monitor

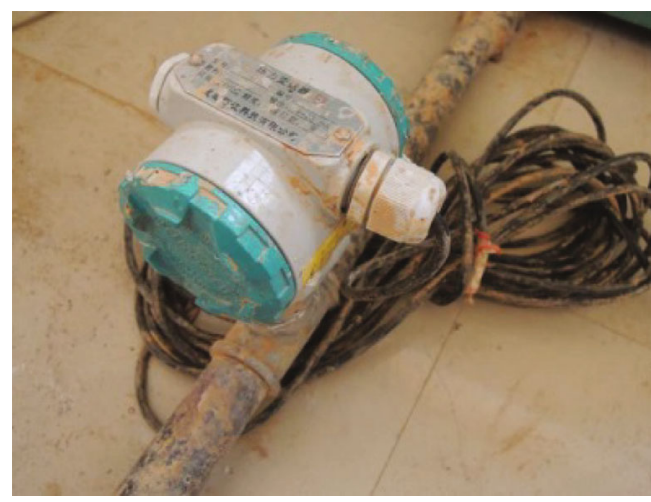

(b) Grouting pressure monitor

FIGURE 3: Grouting data recorder.

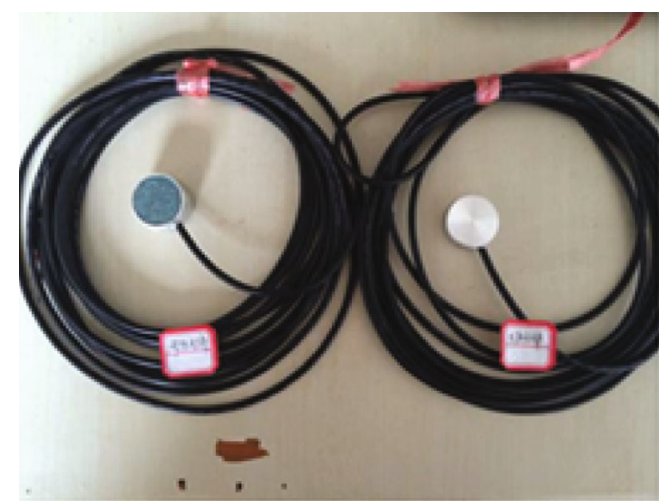

(a) Soil pressure and seepage pressure sensor

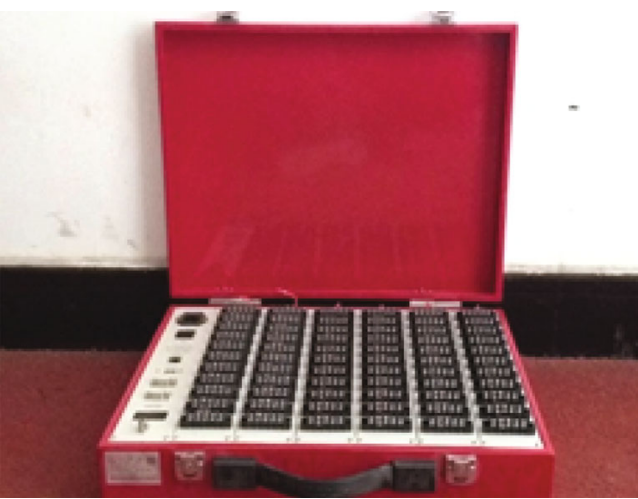

(b) Static strain gauge

Figure 4: Pressure monitoring system. 


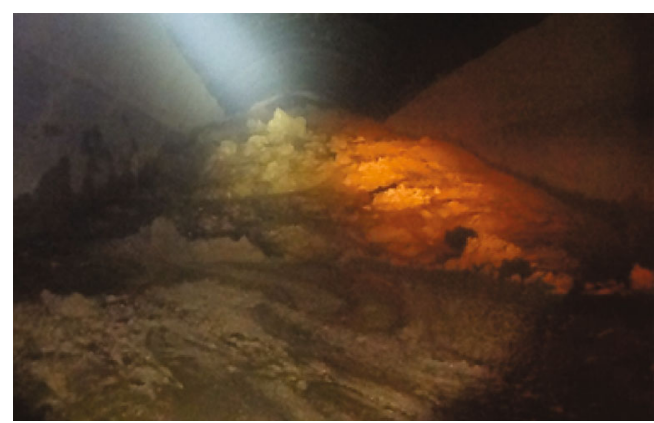

Figure 5: Gush of muddy fillings in F2 fault of Yonglian Tunnel.

cement, which was produced by South cement factory. Accelerator is self-developed by Shandong University which can shorten the setting time of cement grout. The water-cement ratio of the cement component is $W / C=1$. The volume ratio of cement component to accelerator component is $1: 1$. Parameters of grout material used in this test are shown in Table 2. This grout material sets fast with a setting time of $45 \sim 80 \mathrm{~s}$, and its strength grows fast with $1 \mathrm{~h}$ strength of $0.5 \mathrm{MPa}$. In the simulation grouting test, cement-based grout should be injected by a two-shot injection system due to its quick setting characteristics. Two components of grout would be mixed by double components mixer outside the test frame before injection into muddy fillings in the test frame.

3.3. Design of Segmental Grouting Operation. A segmental grouting device was set vertically in the center of the test frame (as shown in Figure 6). There exist three injection holes and two separators in the grouting pipe. Three injection holes are $300 \mathrm{~mm}, 600 \mathrm{~mm}$, and $900 \mathrm{~mm}$ away from the bottom plate, respectively. Two separators are $450 \mathrm{~mm}$ and $750 \mathrm{~mm}$ away from the bottom plate, respectively. The grouting pipe is divided into three sections by two separators, and muddy fillings are divided into three grouted areas correspondingly. In the grouting simulation test, grout was injected into the test frame through the bottom valve. The first grouted area is $450 \mathrm{~mm}$ thick. In the first grouting stage, waterproof sand bags in the two separators were all intact, and grout was prevented from flowing through. As a result, grout was injected into the first grouted area through the injection hole with a height of $450 \mathrm{~mm}$. After the first grouting operation, the waterproof sand bag in the separator with a height of $600 \mathrm{~mm}$ was destroyed by hand-held electric drill, and the second grouting stage can be operated. The second grouted area is $300 \mathrm{~mm}$ thick. In the second grouting stage, grout was injected into the second grouted area through the injection hole with a height of $600 \mathrm{~mm}$. Similarly, in the third grouting stage, grout was injected into the third grouted area with a thickness of $500 \mathrm{~mm}$ through the injection hole with a height of $900 \mathrm{~mm}$.

3.4. Monitoring Plan. Three monitoring sections were set in the test frame which are numbered by sections $\mathrm{A}, \mathrm{B}$, and $\mathrm{C}$ (as shown in Figure 6). Section A and injection hole corresponding to the first grouting stage are at the same height
$(300 \mathrm{~mm})$. In addition, section B and injection hole corresponding to the second grouting stage are at the same height $(600 \mathrm{~mm})$. Section C and injection hole corresponding to the third grouting stage are at the same height $(900 \mathrm{~mm})$. The distribution of soil sensors and seepage sensors in three sections is shown in Figure 7. Six soil pressure sensors and two seepage pressure sensors are set in section A. Sensors A-1, A-2, A-3, and A-4 are set, respectively, $15 \mathrm{~cm}$, $30 \mathrm{~cm}, 45 \mathrm{~cm}$, and $60 \mathrm{~cm}$ away from the center of the injection hole to acquire spatial distribution of soil pressure in fracture grouting process. A-1, A-5, A-6, and A-7 are all set $15 \mathrm{~cm}$ away from the center of the injection hole to acquire total stress, seepage pressure, and effective stress at the same distance to the injection hole. Two soil pressure sensors and two seepage pressure sensors are set in section $\mathrm{B}$ and section $\mathrm{C}$, respectively. These sensors are all set $15 \mathrm{~cm}$ away from the center of the injection hole. Most of soil sensors are set horizontally with vertical stress being monitored. In addition, soil pressure sensor A-6, B-2, and C-2 are set vertically to monitor horizontal stress. Due to equal seepage pressure in all directions, all seepage pressure sensors are set in one direction which is the horizontal direction in this test.

3.5. Grouting Parameters. In the grouting simulation test, the grouting pressure range is $0 \sim 1 \mathrm{MPa}$, and the injection rate range is $0 \sim 5 \mathrm{~L} / \mathrm{min}$. Grout take and grouting pressure were used as end criterion of the grouting process. When grout take reaches $10 \sim 30 \mathrm{~L}$ or grouting pressure reaches $1 \mathrm{MPa}$, grouting operation will stop.

\subsection{Test Procedure}

(1) Filling test frame with muddy fault material and installation of sensors. By stratified compaction, muddy fault material is filled into test frame. When muddy fault material is filled to the height of the monitoring section, soil pressure sensors and seepage pressure sensors are set according to the monitoring plan

(2) Assembly and tightness inspection of grouting pipeline

(3) Debugging of grouting data recorder and pressure field monitoring system

(4) Preparation of grout according to designed watercement ratio of cement component and volume ratio of two components of cement-based quick setting grout

(5) Grouting operation. Three times of grouting operation are done. Interval time between adjacent operations is set as $20 \sim 30 \mathrm{~min}$. In the grouting process, grouting pressure, injection rate, soil pressure field, and seepage pressure field should be monitored in real-time

(6) Clean-up of grouting simulation test system 
TABLE 1: Basic physical parameters of muddy fillings of F2 fault.

\begin{tabular}{lcccccc}
\hline $\begin{array}{l}\text { Dry density } \\
\rho_{\mathrm{d}} /\left(\mathrm{g} \cdot \mathrm{cm}^{-3}\right)\end{array}$ & $\begin{array}{c}\text { Initial water ratio } \\
\omega / \%\end{array}$ & $\begin{array}{c}\text { Permeability efficient } \\
k /\left(\mathrm{cm} \cdot \mathrm{s}^{-1}\right)\end{array}$ & $\begin{array}{c}\text { Liquid limit } \\
\omega_{\mathrm{L}} / \%\end{array}$ & $\begin{array}{c}\text { Plastic limit } \\
\omega_{\mathrm{P}} / \%\end{array}$ & $\begin{array}{c}\text { Cohesion } \\
c / \mathrm{kPa}\end{array}$ & $\begin{array}{c}\text { Internal friction angle } \\
\varphi)^{\circ}\end{array}$ \\
\hline 1.17 & 37.8 & $5.2 \times 10^{-4}$ & 48.3 & 25.6 & 12.3 & 25 \\
\hline
\end{tabular}

TABLE 2: Parameters of grout material.

\begin{tabular}{|c|c|c|c|c|c|c|c|c|c|}
\hline \multirow{2}{*}{ Water cement ratio $W / C$} & \multirow{2}{*}{ Volume ratio of two components } & \multicolumn{2}{|c|}{ Setting time/s } & \multicolumn{6}{|c|}{ Age strength/MPa } \\
\hline & & Initial setting time & Final setting time & $1 \mathrm{~h} 3 \mathrm{~h}$ & $5 \mathrm{~h} 1 \mathrm{~d}$ & $3 \mathrm{~d}$ & $7 \mathrm{~d}$ & $14 \mathrm{~d}$ & $28 \mathrm{~d}$ \\
\hline $1: 1$ & $1: 1$ & 45 & 80 & $0.5 \quad 1.0$ & $1.8 \quad 3.0$ & 7.0 & 7.8 & 8.0 & 8.9 \\
\hline
\end{tabular}

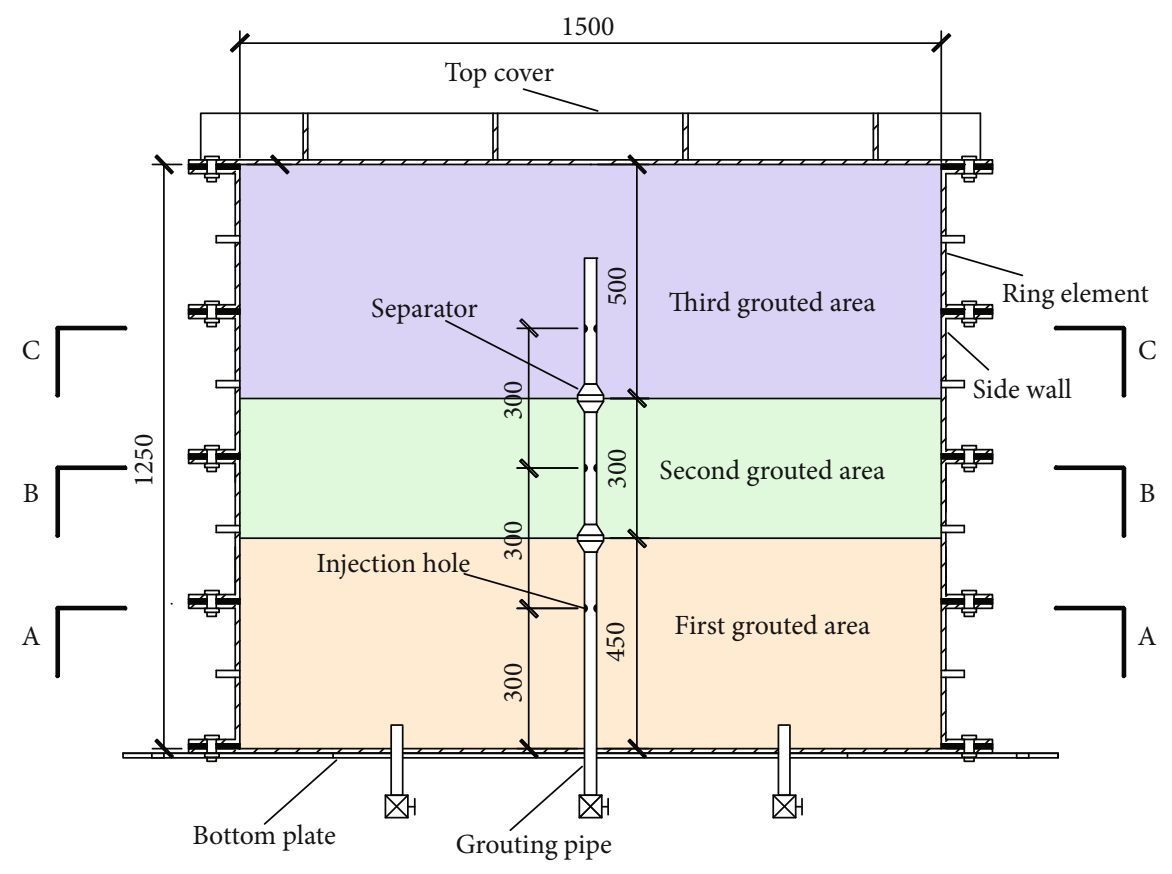

FIGURE 6: Design of segmental grouting operation (unit: mm).

\section{Analysis of Test Results}

4.1. Variation of Grouting Pressure and Injection Rate. In the actual grouting process, the duration of three grouting stages is $150 \mathrm{~s}, 400 \mathrm{~s}$, and $400 \mathrm{~s}$, respectively. Interval time between adjacent grouting stages is $20 \sim 30 \mathrm{~min}$. Due to that, airpowered grouting pump is based on pulse pumping principle, grouting pressure, and injection rate fluctuated over time. Variation of grouting pressure and injection rate with time $(\mathrm{p}-\mathrm{q}-\mathrm{t}$ curves) of three grouting stages is shown in Figure 8.

As shown in Figure 8, grouting pressure and injection rate fluctuate over time within a certain range for three grouting stages, due to the pulse pumping principle. The max grouting pressure of three grouting stages is $0.32 \mathrm{MPa}$, $0.60 \mathrm{MPa}$, and $0.76 \mathrm{MPa}$, respectively, and the max injection rate is $5.60 \mathrm{~L} / \mathrm{min}, 4.53 \mathrm{~L} / \mathrm{min}$, and $4.42 \mathrm{~L} / \mathrm{min}$, respectively. With grouting sequence growing, grouting pressure increases and injection rate decreases. Since compaction and reinforcement of fracture grouting operation, density and mechanical properties of grouted muddy fillings both have been improved. As a result, grouting diffusion will conquer greater resistance in later grouting stages. Consequently, grouting pressure increases and injection rate decreases in later grouting stages.

As described above, the interval distance between adjacent injection holes is $30 \mathrm{~cm}$ for three grouting stages. According to the variation law of grouting pressure and injection rate, grouting operation corresponding to the previous grouting stage has an effect on subsequent grouting operation. It is proved that the influence scope of grouting operation is more than $30 \mathrm{~cm}$. Grout veins and compacted regions produced in different grouting stages overlap with each other, therefore, uniformity of grouted body and reinforcement effect improves significantly.

4.2. Variation of Soil Pressure for Single Grouting Operation. The grouting operation corresponding to the first grouting stage is not affected by the other two grouting stages. Soil pressure sensors A-1, A-2, A-3, and A-4 in monitoring section $\mathrm{A}$ are selected to study the temporal and spatial variation 


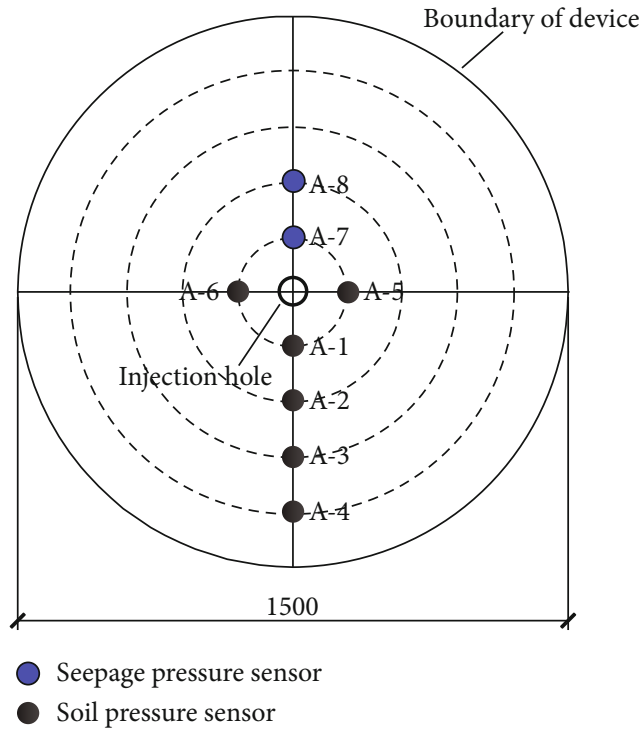

(a) Section $\mathrm{A}$

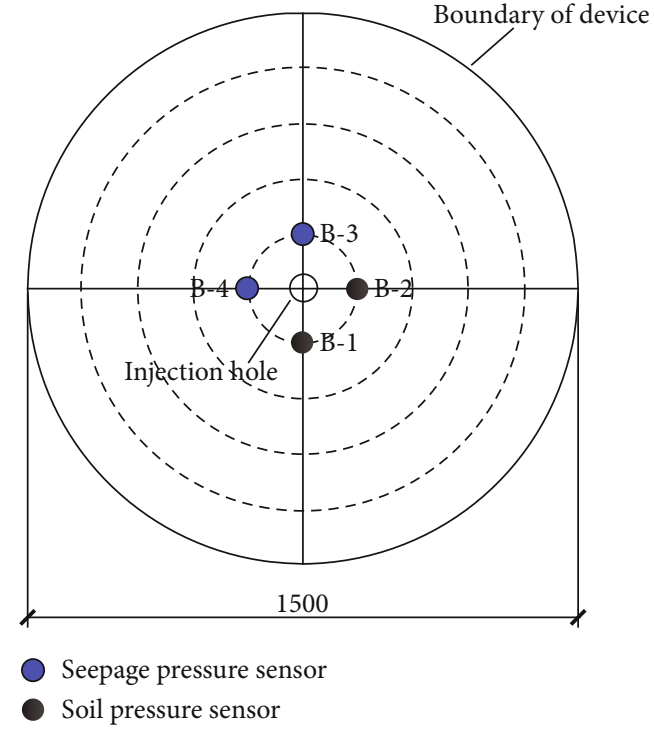

(b) Section B

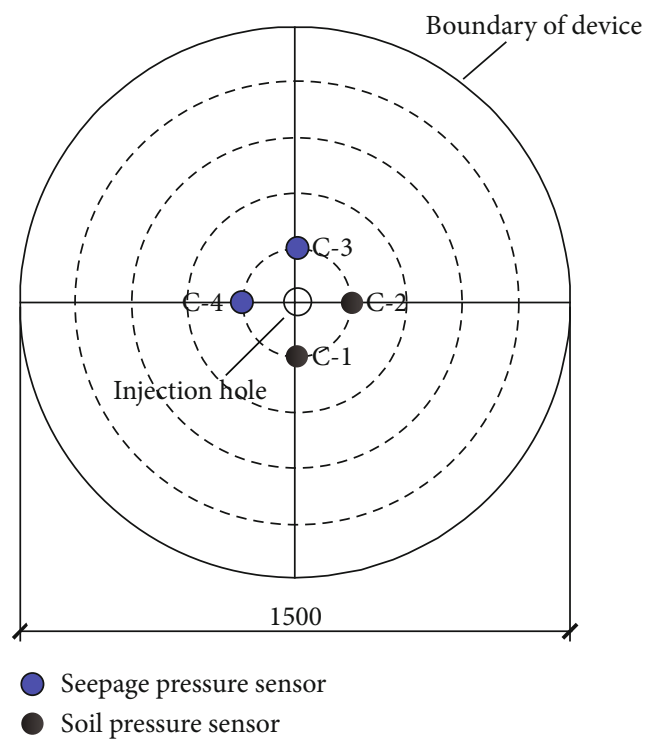

(c) Section C

FIGURE 7: Distribution of soil pressure sensors and seepage pressure sensors (unit: $\mathrm{mm}$ ).

of soil pressure. Variation of soil pressure with time of different location is shown in Figure 9.

Variation of soil pressure field in a single grouting process can be divided into three phases. In a duration of $0 \sim 45 \mathrm{~s}$, soil pressure at different locations fluctuates around $0 \mathrm{MPa}$. It shows that injected grout gathers around the injection hole and compacts the surrounding stratum, with grout bubble forming and no grout vein forming. In a duration of 45 90s, soil pressure at different locations starts to increase, showing that grouting diffusion enters the fracture diffusion phase. Grout vein reaches sensor A-1, A-2, A-3, and A-4 successively. Soil pressure near the injection hole is evidently greater than soil pressure far from the injection hole. It shows that fracture flow of grout needs to conquer evident resistance and grouting pressure decreases along grout diffusion direction. In a duration of $90 \sim 150 \mathrm{~s}$, soil pressure at different locations decreases gradually to a relatively stable value. The reason may be that the grout diffusion front arrives at the boundary of the test frame and new diffusion channel forms which leads to the reduction of grouting diffusion resistance.

The spatial distribution of soil pressure at different moments is shown in Figure 10.

(1) With distance to injection hole increasing, soil pressure decreases nonlinearly. Soil pressure decreases faster in the area near the injection hole than that in the area near the diffusion front. The reason is that flow velocity in the area near the injection hole is higher than that in the area near the diffusion front. Correspondingly, there is more diffusion resistance 


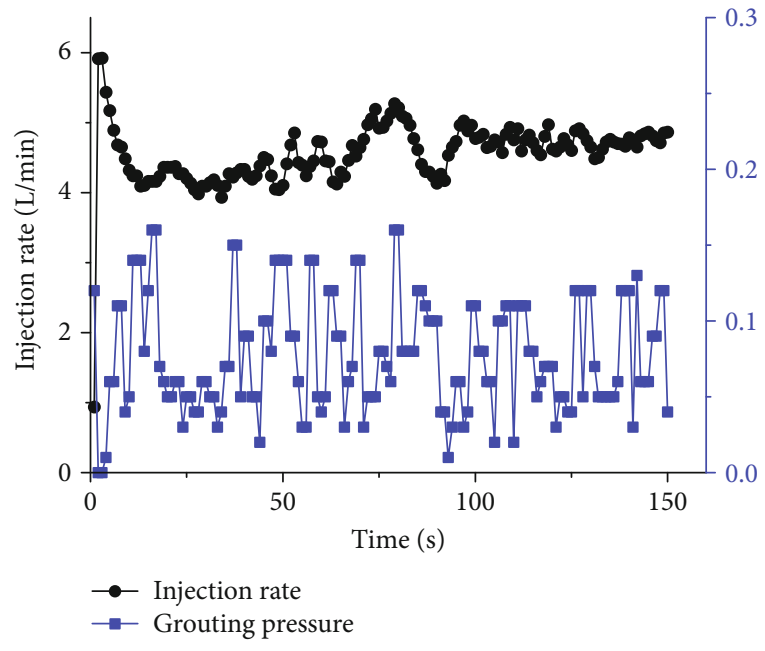

(a) First grouting stage

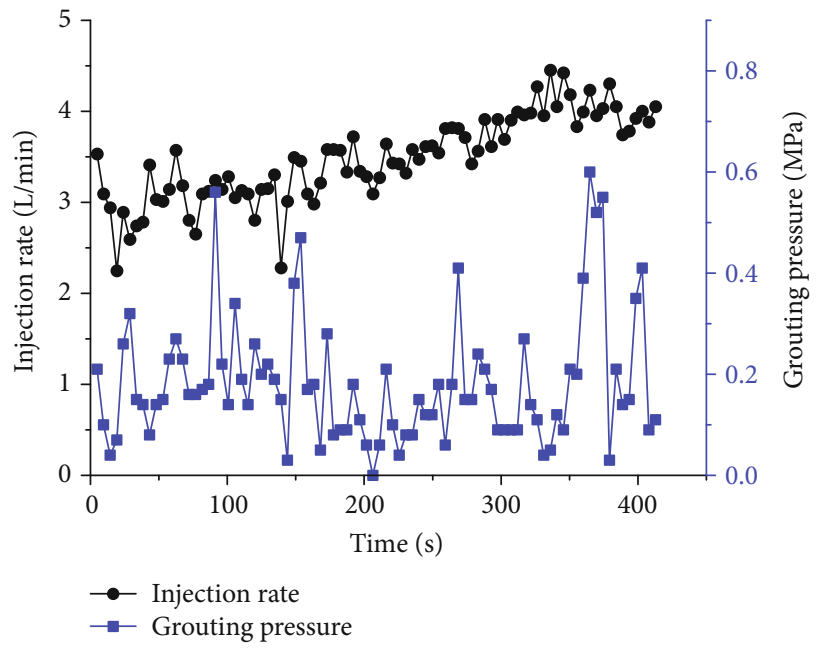

(b) Second grouting stage

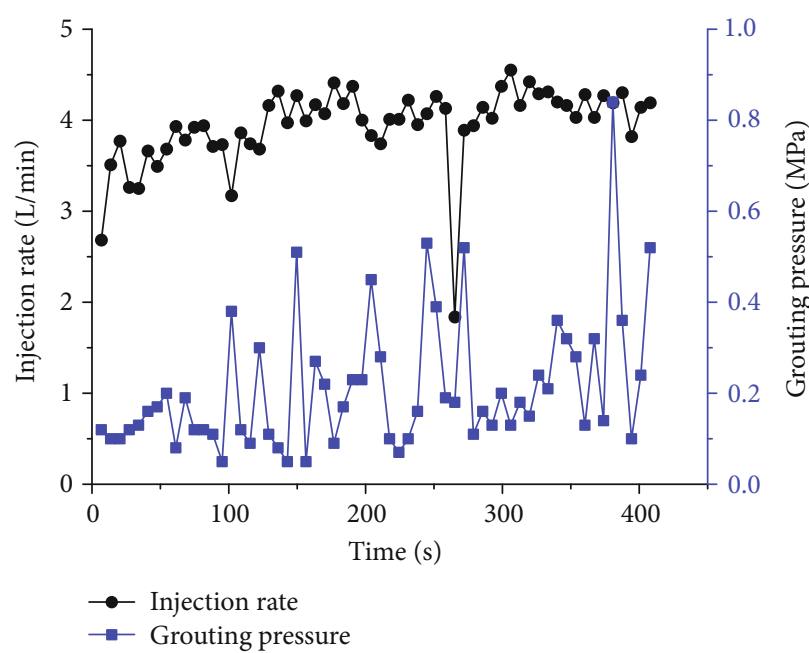

(c) Third grouting stage

FIGURE 8: p-q-t curves of three grouting stages.

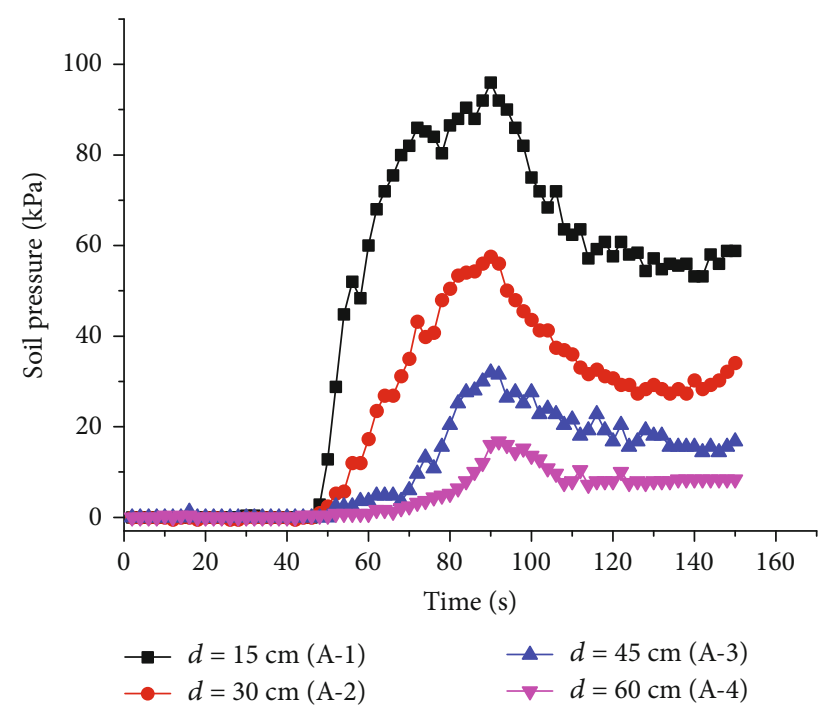

FIGURE 9: Variation of soil pressure with time of different locations. of grouting diffusion and a higher decay rate in the area near the injection hole than that in the area near the diffusion front

(2) As grouting operation going on, soil pressure decreases faster along diffusion direction. Yield stress and viscosity of grout increase with grout gel reaction. Grouting diffusion should conquer more flow resistance, which is why soil pressure decreases faster along diffusion direction with time growing

4.3. Variation of Soil Pressure for Segmental Grouting Operation. In the grouting simulation test, the soil pressure field and seepage pressure field are monitored continuously at three monitoring sections. The grouting duration of every grouting stage is in the range of $150 \sim 400 \mathrm{~s}$. By contrast, the interval time between adjacent grouting stages is $20 \sim 30 \mathrm{~min}$. Discovered from monitoring data, soil pressure and seepage pressure maintains basic stability between adjacent grouting stages. In order to better express the trend of 


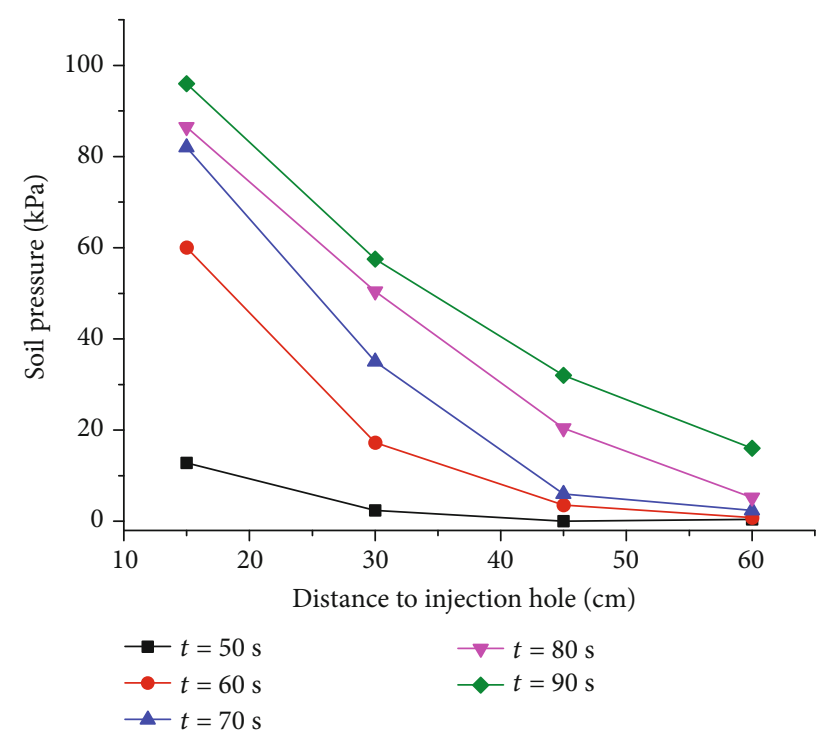

FIGURE 10: Spatial distribution of soil pressure at different moments.

pressure changes, part of the pressure data between adjacent grouting stages is omitted in data curves. Variation of soil pressure with time in three grouting stages is shown in Figure 11. For convenient comparison, pressure data in Figure 11 all comes from pressure sensors with a distance to the injection hole of $15 \mathrm{~cm}$.

(1) In the first grouting stage, the soil pressure change trend of two sensors with the same distance to the injection hole is basically consistent, whose maximum error does not exceed $15 \mathrm{kPa}$. In the second and third grouting stages, the soil pressure change trend of two sensors with the same distance to the injection hole is extremely consistent. It shows that grout diffuses uniformly and radially around from the injection hole in three grouting stages. And there does not exist a specific diffusion channel. In addition, in three stages, the soil pressure change trend of sensors set horizontally is basically consistent with that of sensors set vertically. It shows that the effect of grouting diffusion on vertical soil pressure and horizontal soil pressure is the same basically

(2) In three grouting stages, soil pressure increases fast in grouting duration. Furthermore, soil pressure decreases from peak value after grouting operation and gradually stabilizes at a certain value. It is worth noting that stable soil pressure after grouting operation is higher than stable soil pressure before the grouting operation for the second and third grouting stages. This means that diffusion of grout veins improves compaction stress and effectively compact grouted stratum. Partial compaction stress would dissipate after grouting operation. However, there still exists a certain value of compaction stress in grouted stratum, which reflects the reinforcement effect of grouting on the stratum
(3) Max soil pressure in different grouting stages is shown in Figure 12. The injection hole of the first grouting stage is located in section A. By contrast, injection holes of the second and third grouting stages are, respectively, $30 \mathrm{~cm}$ and $60 \mathrm{~cm}$ away from section A. For section A, the max soil pressures in the first grouting stage $(103 \mathrm{kPa}$ and $92 \mathrm{kPa})$ are higher than that in the last two grouting stages. Effect of grouting operation in the second and third grouting stages on soil pressure in section A is relatively weak. It means that there exists an influence range for grouting operation. With distance to injection hole increasing, compaction degree of grouted stratum caused by grouting operation weakens. This phenomenon also occurs in section $\mathrm{B}$ and section $\mathrm{C}$. For section $\mathrm{B}$, the injection hole of the second grouting stage is located in section B. The max soil pressures in the second grouting stage are higher than that in other grouting stages. For section $\mathrm{C}$, the injection hole of the third grouting stage is located in section C. The max soil pressures in the third grouting stage are higher than that in other grouting stages

4.4. Variation of Seepage Pressure and Effective Stress for Segmental Grouting Operation. Variation of seepage pressure and effective stress with time in three grouting stages is shown in Figure 13.

In three grouting stages, the change trend of seepage pressure is basically consistent with that of soil pressure. In grouting duration, seepage pressure increases fast. Furthermore, seepage pressure decreases from peak value after grouting operation and gradually stabilizes at a certain value. Stable seepage pressure after grouting operation is higher than stable seepage pressure before the grouting operation for the second and third grouting stages. Seepage pressure decreases very slowly in the interval time between adjacent grouting operations, which shows that excess pore water pressure has not enough time to dissipate in the interval time. Muddy fault has low permeability, resulting that consolidation speed is slow.

In sections $\mathrm{A}, \mathrm{B}$, and $\mathrm{C}$, there simultaneously exist soil pressure sensors and seepage pressure sensors with a distance to injection hole of $15 \mathrm{~cm}$. The difference between soil pressure and seepage pressure with the same distance to the injection hole can reflect effective stress. Variation of effective stress in different grouting stages is shown in Figure 14. High effective stress is corresponding to a good reinforcement effect. Effective stress in three sections all increase after every grouting stage, showing that muddy fault is compacted and effectively reinforced by three times of grouting operation.

The injection hole of the first grouting stage is located in section A. Section B and section C are located $30 \mathrm{~cm}$ and $60 \mathrm{~cm}$ away from the injection hole, respectively. For section A, the growth value of effective stress corresponding to the first grouting stage is higher than that of other grouting stages. Affected by the second and third grouting operation, muddy fault is compacted, and effective stress improves successively. The function of the second and third grouting stage is supplemental reinforcement. It shows that there exists an 


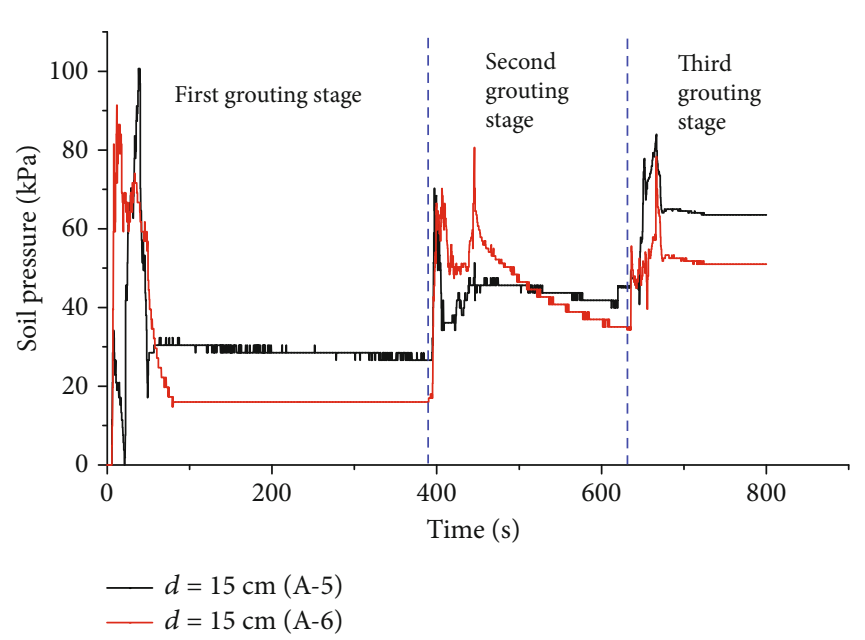

(a) Section $\mathrm{A}$

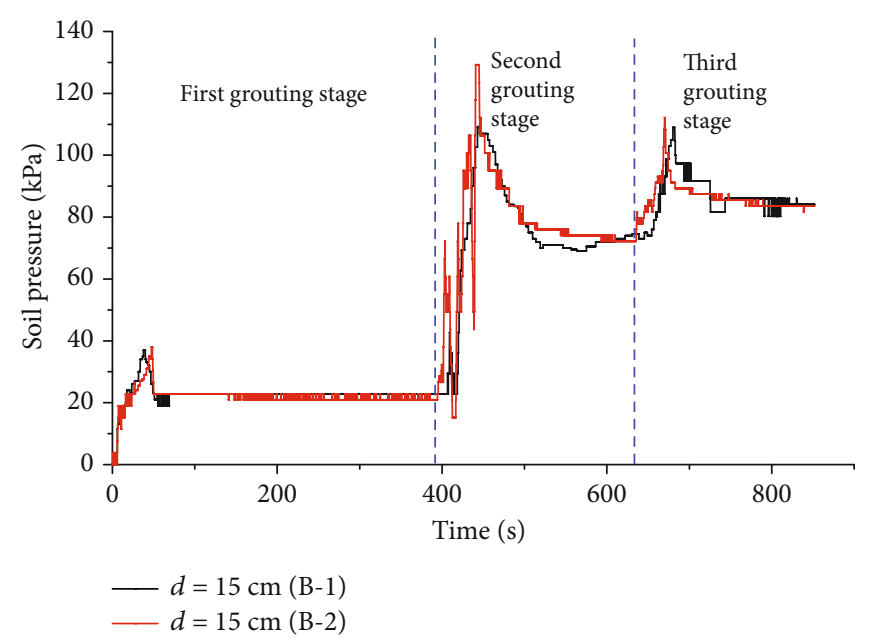

(b) Section B

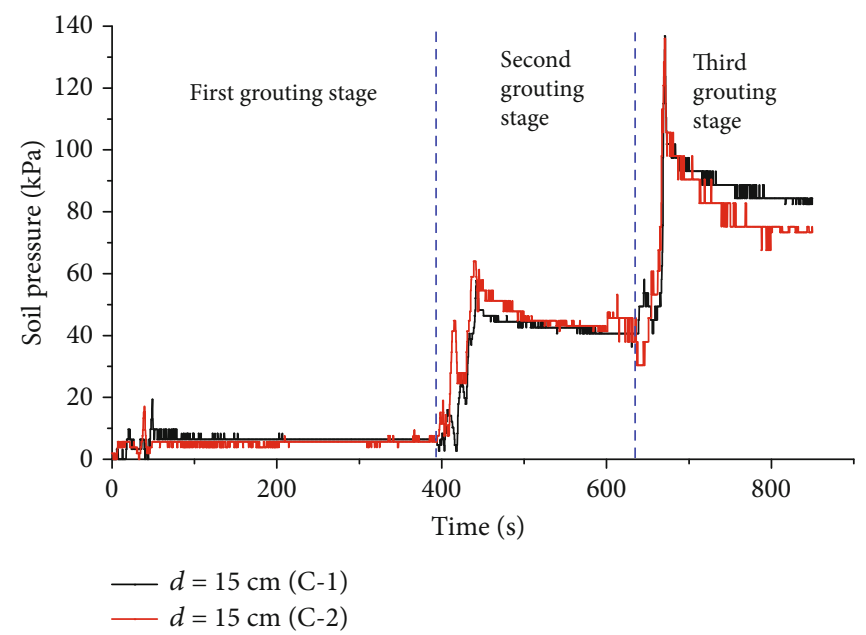

(c) Section C

FIGURE 11: Variation of soil pressure with time in three grouting stages.

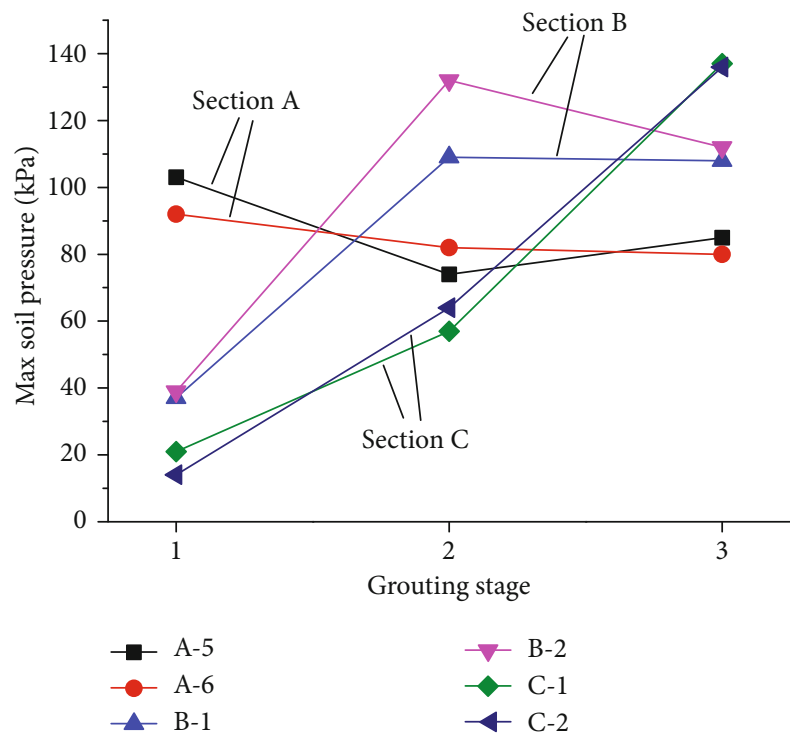

Figure 12: Max soil pressure in different grouting stages. influence range for grouting operation. With distance to injection hole increasing, compaction degree of grouted stratum and reinforcement effect decreases in space. For section $\mathrm{B}$, the injection hole of the second grouting stage is located in section $\mathrm{B}$, resulting that growth value of effective stress corresponding to the second grouting stage is higher than that of other grouting stages. The first and third grouting operation can cause the growth of effective pressure and reinforce muddy fault. However, the contribution of these two grouting operations is smaller than the second grouting operation. In other words, the second grouting operation is the main reinforcement process, and the other two grouting operations reinforce muddy fault supplementally. The same situation applies to section $C$, in which the third grouting operation is the main reinforcement process and the other two grouting operations reinforce muddy fault supplementally.

From aspects of variation of soil pressure and effective stress in grouted stratum, there exists a limited influence range for single grouting operation. With distance to injection hole increasing, compaction degree and reinforcement 


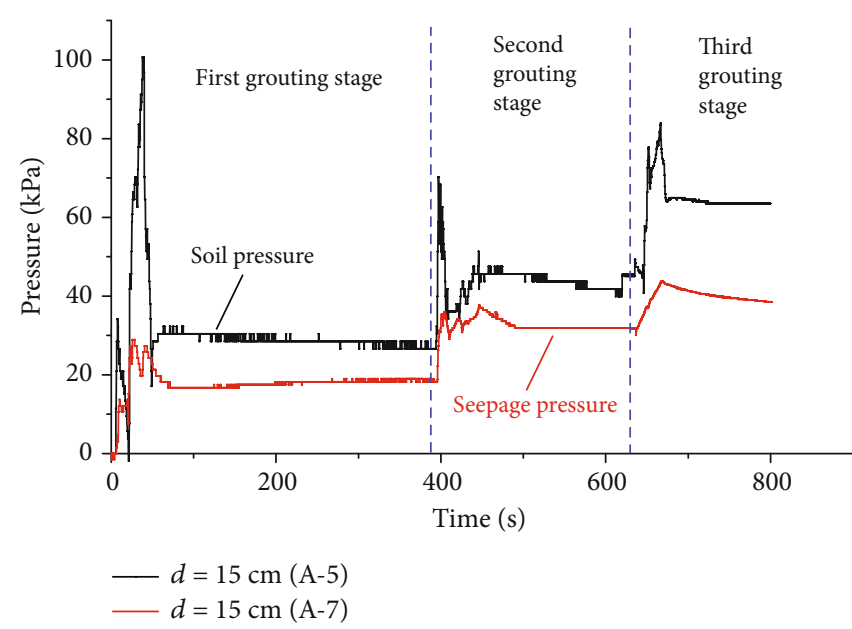

(a) Section $\mathrm{A}$

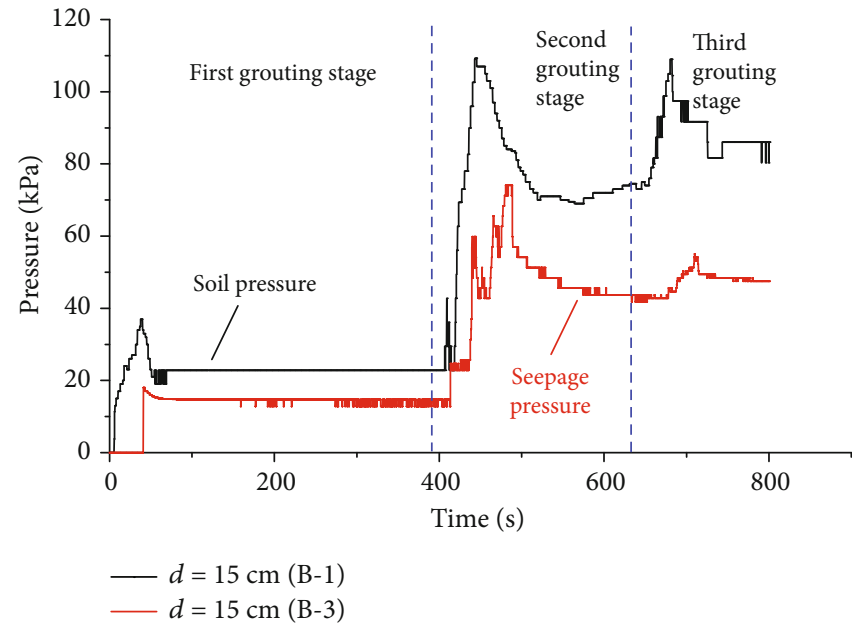

(b) Section B

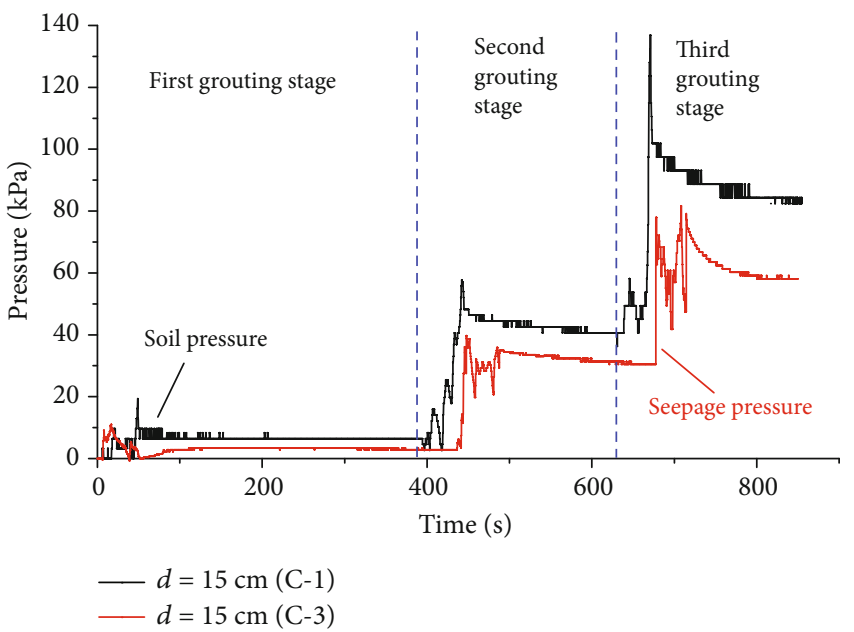

(c) Section C

FIGURE 13: Variation of seepage pressure with time in three grouting stages.

effect of grouted muddy fault decays in space. Multisegmental grouting method has significant advantages over the single grouting method. Ineffectively compacted area by previous grouting operation can be effectively compacted by later grouting operation from adjacent injection hole. As a result, uniformity of grouting reinforcement effect can be improved, and weak reinforcement area can be reduced. Therefore, the segmental grouting method should be adopted preferentially to reinforce muddy fault in tunneling projects.

\section{Conclusion}

(1) Previous grouting operation can affect later grouting operation. Due to previous grouting operation, the grouted stratum can be compacted and grouting diffusion will conquer greater resistance in later grouting stages. Correspondingly, grouting pressure increases and injection rate decreases

(2) For a single grouting operation, soil pressure rises first and then falls in grouting duration. With dis- tance to injection hole increasing, soil pressure decreases nonlinearly. As grouting operation going on, soil pressure decreases faster along diffusion direction

(3) In grouting operation, soil pressure increases fast in grouting duration. After grouting operation, soil pressure decreases from peak value and gradually stabilizes at a certain value. Furthermore, stable soil pressure after grouting operation is higher than stable soil pressure before the grouting operation, which means that diffusion of grout veins improves compaction stress and effectively compact grouted stratum

(4) From aspects of variation of soil pressure and effective stress in grouted stratum, there exists a limited influence range for single grouting operation. For every grouting stage, soil pressure and effective stress in the section which the injection hole locates in is affected effectively by grouting operation. By contrast, soil pressure and effective stress in section away 


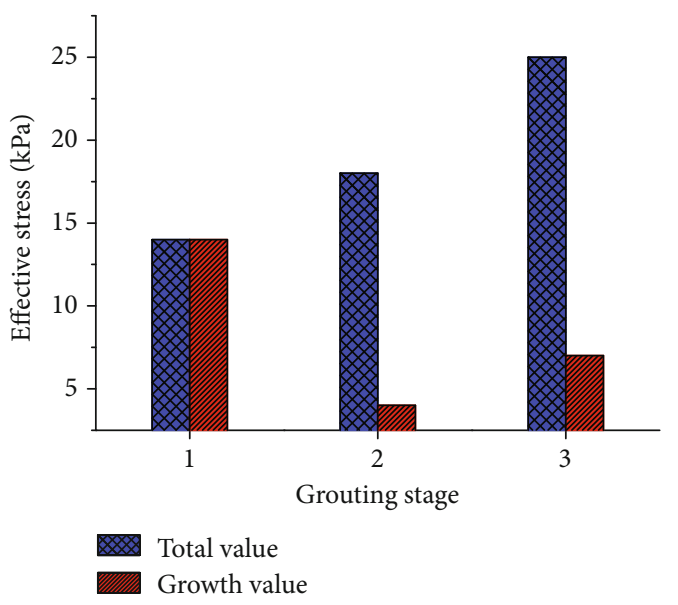

(a) Section $\mathrm{A}$

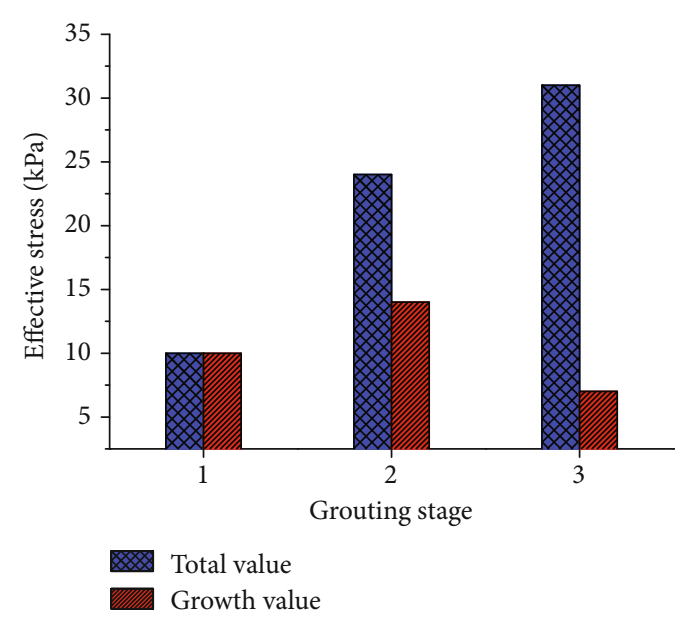

(b) Section B

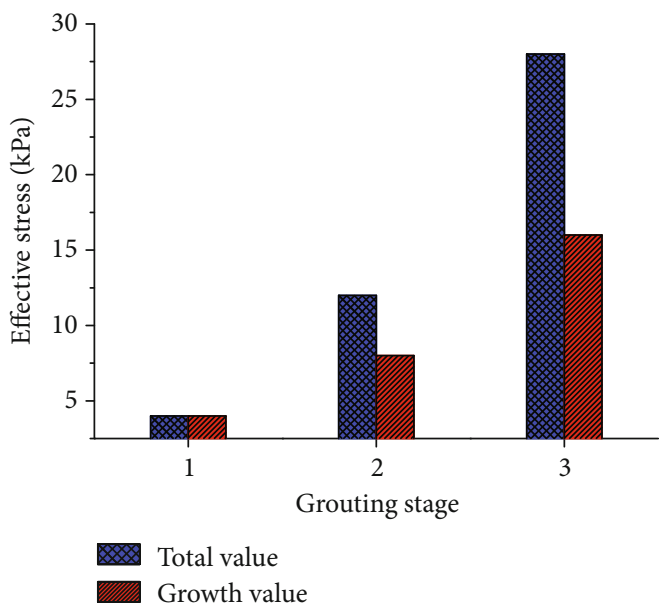

(c) Section C

FIGURE 14: Variation of effective stress in different grouting stages.

from injection hole is affected relatively weakly by grouting operation. With distance to injection hole increasing, compaction degree and reinforcement effect of grouted muddy fault decays in space

(5) Multisegmental grouting method has significant advantages over the single grouting method. Ineffectively compacted area by previous grouting operation can be effectively compacted by later grouting operation from adjacent injection hole. As a result, uniformity of grouting reinforcement effect can be improved, and weakly reinforcement area can be reduced

\section{Data Availability}

The data used to support the findings of this study are available from the corresponding author upon request.

\section{Conflicts of Interest}

The authors declare that they have no conflicts of interest.

\section{Acknowledgments}

This work was supported by the National Key Research and Development Project (2020YFB1600500); the National Natural Science Foundation of China (U1706223, 51779133, 51909270, and 51909147).

\section{References}

[1] S. Li, R. Liu, Q. Zhang, and X. Zhang, "Protection against water or mud inrush in tunnels by grouting: a review," Journal of Rock Mechanics and Geotechnical Engineering., vol. 8, no. 5, pp. 753-766, 2016.

[2] L. Zhang, Study on Penetration and Reinforcement Mechanism of Grouting in Sand Layer Disclosed by Subway Tunnel and its Application, Shandong University, 2017.

[3] L. Li, S. Sun, J. Wang, W. Yang, S. Song, and Z. Fang, "Experimental study of the precursor information of the water inrush in shield tunnels due to the proximity of a water-filled cave," International Journal of Rock Mechanics and Mining Sciences, vol. 130, p. 104320, 2020.

[4] L. Li, S. Sun, J. Wang, S. Song, Z. Fang, and M. Zhang, "Development of compound EPB shield model test system for 
studying the water inrushes in karst regions," Tunnelling and Underground Space Technology, vol. 101, article 103404, 2020.

[5] Q. Wang, S. Wang, S. W. Sloan, D. Sheng, and R. Pakzad, "Experimental investigation of pressure grouting in sand," Soils and Foundations, vol. 56, no. 2, pp. 161-173, 2016.

[6] R. Mozumder, A. Laskar, and M. Hussain, "Penetrability prediction of microfine cement grout in granular soil using artificial intelligence techniques," Tunnelling and Underground Space Technology, vol. 72, pp. 131-144, 2018.

[7] Z. Li, L. Zhang, Y. Chu, and Q. Zhang, "Research on influence of water-cement ratio on reinforcement effect for permeation grouting in sand layer," Advances in Materials Science and Engineering, vol. 2020, Article ID 5329627, 12 pages, 2020.

[8] A. Panah and E. Yanagisawa, "Laboratory studies on hydraulic fracturing criteria in soil," Soils and Foundations, vol. 29, no. 4, pp. 14-22, 1989.

[9] P. G. Nicholson, Soil Improvement and Ground Modification Methods, Elsevier Inc., 2015.

[10] D. M. Zhang, Z. K. Huang, Z. Y. Yin, L. Z. Ran, and H. W. Huang, "Predicting the grouting effect on leakage-induced tunnels and ground response in saturated soils," Tunnelling and Underground Space Technology, vol. 65, pp. 76-90, 2017.

[11] D.-M. Zhang, Z.-K. Huang, R.-L. Wang, J.-Y. Yan, and J. Zhang, "Grouting-based treatment of tunnel settlement: practice in Shanghai," Tunnelling and Underground Space Technology, vol. 80, pp. 181-196, 2018.

[12] M. Marchi, G. Gottardi, and A. K. Soga, "Fracturing pressure in clay," Journal of Geotechnical and Geoenviromental Engineering, vol. 140, no. 2, article 04013008, 2014.

[13] Q. Zhang, P. Li, X. Zhang, S. Li, W. Zhang, and Q. Wang, "Exploration and grouting of large-scale water capsule in the fault fracture zone of Yonglian tunnel," The Open Civil Engineering Journal, vol. 9, pp. 32-43, 2015.

[14] Z. Li, S. Li, H. Liu, Q. Zhang, and Y. Liu, "Experimental study on the reinforcement mechanism of segmented split grouting in a soft filling medium," Processes, vol. 6, no. 8, p. 131, 2018.

[15] S. Zhou and J. Chen, "Hydrofracture grouting in soft flowing mucky ground for a metro tunnel," Chinese Journal of Geotechnical Engineering, vol. 24, no. 2, pp. 222-224, 2002.

[16] A. Bezuijen, Compensation Grouting in Sand, Experiments, Field Experiences and Mechanisms, Wormann Print Service, Netherlands, 2010.

[17] F. Sun, T. Chen, D. Zhang, Z. Zhang, and P. Li, "Study on fracture grouting mechanism in subsea tunnel based on Bingham fluids," Journal of Beijing Jiaotong University, vol. 33, no. 4, pp. 1-6, 2009.

[18] F. Sun, D. Zhang, and C. Chen, "Fracture grouting mechanism in tunnels based on time-dependent behaviors of grout," Chinese Journal of Geotechnical Engineering, vol. 33, no. 1, pp. 88-93, 2011.

[19] T. Chen, L. Zhang, and D. Zhang, "An FEM/VOF hybrid formulation for fracture grouting modelling," Computers and Geotechnics, vol. 58, pp. 14-27, 2014.

[20] S. Li, W. Zhang, Q. Zhang et al., "Research on advantagefracture grouting mechanism and controlled grouting method in water-rich fault zone," Rock and Soil Mechanics, vol. 35, no. 3, pp. 744-752, 2014.

[21] J. Yuan, W. Chen, X. Tan, and H. Wang, "Mesomechanical simulation of grouting in weak strata," Rock and Soil Mechanics, vol. 32, no. S2, pp. 653-659, 2011. 